\title{
Nutrient Composition of Pre-treated Foxtail Millet Rice
}

\author{
Smita Doddamani* and Nirmala B. Yenagi \\ Department of Food Science and Nutrition, \\ College of Rural Home Science, UAS, Dharwad-580 005, India \\ *Corresponding author
}

\section{A B S T R A C T}

The present study was conducted to know the nutrition composition of pre-treated foxtail millet rice in comparison with raw foxtail millet grains. Different pre-treatments were given to the millet grains in different combination such as roasting; cooking, drying and roasting. Pre-treatment reduced the moisture, protein, fat content of millet grains significantly $(\mathrm{p}<0.05)$. More reduction was observed in cooked, dried and roasted grains and minimum reduction was observed in roasted grains. There was no significant difference observed in ash content. Carbohydrate content increased more in cooked, dried and roasted grains $(62.14 \mathrm{~g})$ than roasted grains $(56.77 \mathrm{~g})$. Roasting increased insoluble dietary fibre $(12.95 \mathrm{~g})$ and total dietary fibre $(13.60 \mathrm{~g})$ whereas it decreased in cooked, dried and roasted grains (10.70 and $11.05 \mathrm{~g})$. Resistant starch content increased significantly in pre-treated grains. Maximum increase was observed in cooked, dried and roasted grains $(3.03 \mathrm{~g})$ and minimum increase was observed in roasted grains $(2.14 \mathrm{~g})$. Pretreatments did not affected the iron, zinc and manganese content of grains whereas it decreased the calcium content and increased the copper content significantly $(\mathrm{p}<0.05)$. More reduction in calcium was observed in cooked, dried and roasted grains $(28.50 \mathrm{mg})$ than roasted grains $(31.84 \mathrm{mg})$. Pre-treatment, roasting increased the total phenolic content (46.77mgGAE $/ 100 \mathrm{~g}$ ) of millet grains whereas cooked, dried and roasting reduced the phenols $(26.73 \mathrm{mgGAE} / 100 \mathrm{~g})$. Similar trend was observed in DPPH activity. It increased in roasted grains $(38.62 \%)$ and decreased in cooked, dried and roasted grains $(24.45 \%)$.

\section{Introduction}

In recent years, millets have been recognized as important substitutes for major cereal crops to cope up with the world foods storage and to meet the demands of increasing population of both developing and developed countries (Shree et al., 2008). Millets are very high in their nutrition content. Millets are rich in B vitamins, calcium, iron, potassium, magnesium, zinc, also gluten-free and has
low-GI (Glycemic index). Minor millets are the storehouse of many chemical components including nutrients, phyto-chemicals and nonnutritive functional constituents. The nutritive value of millets is comparable to other cereals with slightly higher content of protein and minerals (Gopalan et al., 2007). The average protein content in foxtail millet was reported to be about 11.07 per cent (Veena et al., 2005). Kumar and Parameshwaran (2006) found that foxtail millet recorded a fat content 
ranging from 2.3 to 5.9 per cent. Simple processing of foxtail millet-like dehulling, soaking, and cooking resulted in a significant decrease in antinutrients such as polyphenols and phytate, and improved the bioavailability of minerals such as iron and zinc and also protein digestibility in vitro (Pawar and Machewad, 2006). Thermal processing, mechanical processing, soaking, fermentation, and germination/malting increase the physicochemical accessibility of micronutrients, decrease the content of antinutrients, such as phytates, or increase the content of compounds that improve bioavailability (Hotz and Gibson, 2007).

Chandrasekara et al., (2012) studied effect of processing on antioxidant activities on several millet grains, namely kodo, finger (Ravi), finger (local), proso, foxtail, little and pearl millet. Antioxidant activities of phenolic extracts obtained from whole grains, as well as their corresponding dehulled and cooked grains and hulls were studied for their total phenolic content (TPC), radical scavenging capacity, and antioxidant activity in a carotene/linoleate emulsion. The phenolics present in whole grains were identified and quantified using HPLC and HPLC/MS and results were expressed as total for each of the phenolic groups. The TPC ranged from 2 to 112 molferulic acid equivalents/g defatted meal. All varieties exhibited effective inhibition of 2,2-diphenyl-1-picrylhydrazyl (DPPH), hydroxyl, peroxyl and superoxide radicals. Dehulling and cooking affected the TPC and radical scavenging and antioxidant activities of the grains, depending on the variety. In general, the antioxidant activity of phenolic extracts was in the order of hull > whole grain >dehulled grain > cooked dehulled grain.

Jamima and Indu (2012) studied the nutrient composition of processed foxtail and proso millets by various cooking methods like wet heating (boiling, blanching, soaking and germination) and dry-heating (roasting) and to compare the antioxidant activity of processed minor millets in relationship with their total phenolic content. Soaked samples of foxtail and proso millet showed higher scavenging activity which was found to be 51.06 and 52.12 per cent respectively. The antioxidant power of roasted foxtail millet and blanched proso millet had significant increase ranging about $(317.5 \mu \mathrm{mol}$ and $236.8 \mu \mathrm{mol}$ ) respectively using FRAP assay. The blanched samples had higher reducing power indicating enhanced antioxidant activity i.e. (0.426 and 0.418) respectively. The phytochemical content was determined qualitatively. The blanched and germinated millet samples possessed higher antioxidant activity.

Khapre et al., (2016) studied the effect of roasting on nutritional and anti-nutritional components of foxtail millet (Setaria italica). Foxtail millet was roasted in a shallow pan at $95^{\circ} \mathrm{C}$ for 5-7 min. Application of roasting treatment significantly decreased the moisture (8.9 to $3.7 \%$ ) and slightly reduced the fiber (5.66 to $5.49 \%$ ), carbohydrate (70.5 to 70.3 $\%$ ), protein (12.1 to $10.8 \%$ ), fat (1.93 to 1.86 $\%$ ), potassium (128.8 to $122.5 \mathrm{mg} / 100 \mathrm{~g}$ ) and magnesium (72 to $55 \mathrm{mg} / 100 \mathrm{~g}$ ). Roasting increased the iron (2.92 to $3.1 \mathrm{mg} / 100 \mathrm{~g}$ ), calcium (41 to $42.1 \mathrm{mg} / 100 \mathrm{~g}$ ) and phosphorous (280.1 to $281.7 \mathrm{mg} / 100 \mathrm{~g}$ ). Roasting also significantly reduced the antinutrients like polyphenols (14.5 to $7.8 \mathrm{mg}$ GAE/100 g), tannins (221.1 to $92.4 \mathrm{mg}$ $\mathrm{CAE} / 100 \mathrm{~g}$ ) and phytic acid (306 to 180.5 $\mathrm{mg} / 100 \mathrm{~g}$ ).

Results of study revealed that the roasting of foxtail millet found to be beneficial in terms of nutritional characteristics. Hence the present study was carried out to know the changes in nutrient composition of pre-treated foxtail millet grains. 


\section{Materials and Methods}

\section{Procurement of foxtail millet}

Commercially available decorticated foxtail millet (Setaria italica) grains was procured in bulk from the miller of village, Timmapur, Haveri District, stored in cold storage room and used throughout the research work.

\section{Pre-treatments}

Different pre-treatments were given to the millet grains in different combination such as roasting; cooking, drying and roasting. Detailed procedure is given in the table 1.

\section{Nutrient composition of pre-treated foxtail} millet grains

\section{Proximate composition}

The samples were ground into fine powder, defatted and packed in zip lock pouches and stored in a desiccator and used for analysis of proximate composition except for fat.

The moisture, protein, fat and ash contents were analyzed by following standard AOAC methods (AOAC, 2005) and were expressed in $\mathrm{g} / 100 \mathrm{~g}$. The soluble, insoluble and total dietary fiber fractions were analyzed by gravimetric, enzymatic method given by Asp et al., (1983).

\section{Resistant starch}

The resistant starch content was determined using the megazyme kit (K-RSTAR 09/14). Samples were incubated in a shaking water bath with pancreatic $\alpha$-amylase and amyloglucosidase (AMG) for $16 \mathrm{hr}$ at $37^{\circ} \mathrm{C}$, during which time non-resistant starch was solubilised and hydrolysed to D-glucose by the combined action of the two enzymes. The reaction is terminated by the addition of an equal volume of ethanol or industrial methylated spirits (IMS, denatured ethanol), and the RS is recovered as a pellet on centrifugation. This was then washed twice by suspension in aqueous IMS or ethanol $(50 \%$ $\mathrm{v} / \mathrm{v})$, followed by centrifugation. Free liquid was removed by decantation. RS in the pellet is dissolved in $2 \mathrm{M} \mathrm{KOH}$ by vigorously stirring in an ice-water bath over a magnetic stirrer. This solution is neutralized with acetate buffer and the starch is quantitatively hydrolysed to glucose with AMG. D-Glucose is measured with glucose oxidase/peroxidase reagent (GOPOD), and this is a measure of the RS content of the sample.

\section{Minerals}

Calcium was estimated by following titrimetric method. Calcium was precipitated as oxalate and titrated against standard potassium permanganate (AOAC, 2005). The micronutrients (iron, zinc, copper and manganese) were estimated by wet digestion using triacid mixture (AOAC, 2005). A known aliquot of test sample was suitably diluted and micronutrients in the test sample $(\mathrm{Cu}, \mathrm{Mn}, \mathrm{Zn}$ and $\mathrm{Fe}$ ) were determined using Atomic Absorption Spectrophotometer.

\section{Polyphenol and per cent DPPH activity}

Total phenol estimation was carried out with the Folin-Ciocalteau reagent. Phenols react with phosphomolybdic acid in FolinCiocalteau reagent in alkaline medium and produce blue coloured complex (molybdenum blue). Gallic acid was used as the standard. The antioxidant assay was carried out according to the procedure by $\mathrm{Yu}$ et al., (2002) using DPPH (2, 2-diphenyl-1picrylhydrazyl) as free radical method.

\section{Statistical analysis}

All chemical analyses was performed in triplicates $(n=3)$ and the data was presented as mean \pm SD. To know the difference between 
the proximate composition, dietary fiber composition, mineral composition, polyphenol and antioxidant of pre-treated grains, statistical analysis one way ANOVA was carried out using SPSS (Statistical Packages for Social Sciences) software version 16.0.

\section{Results and Discussion}

\section{Proximate composition}

Table 2 shows proximate composition of raw and pre-treated foxtail millet grains. Proximate composition except ash of different pre-treated millet grains varied significantly $(\mathrm{p}<0.01)$. Moisture content of raw foxtail millet grain was 9.27 per cent. Pre-treatment significantly decreased the moisture content. Maximum reduction was observed in cooked, dried and roasted $(3.68 \%)$ grains followed by roasted $(4.48 \%)$ grains. As expected, significant reduction in moisture content may be due to evaporation of moisture during roasting. Similar results were reported by Khapreet al. (2016) i.e. reduction in moisture of foxtail millet was due to use of roasting as a dry heat processing method.

Fat content of raw foxtail millet grain was 4.86 g. Pre-treatment significantly decreased the fat content. Maximum reduction was observed in cooked, dried and roasted $(2.71 \mathrm{~g})$ grains followed by roasted (4.22 g) grains. Significant reduction in fat content may be due to oxidation and degradation of fat during processing.

There was no significant difference was observed in ash content. Protein content of raw foxtail millet grain was 16.08 g. Pretreatment significantly decreased the protein content. Significant reduction in protein may be due to leaching of soluble protein. Maximum reduction was observed in cooked, dried and roasted $(14.07 \mathrm{~g})$ grains and minimum was observed in roasted grains $(15.40 \mathrm{~g})$.Similar result was reported by Osaretinet al. (2007) that Loss of protein may be due to leaching of soluble protein and denaturation of protein during cooking of rice and also and change in the protein content of roasted grain could be due to loss of amino acids (Sade, 2009). Total dietary fiber result is discussed in the dietary fiber section. Carbohydrate content of raw foxtail millet grain was $16.08 \mathrm{~g}$. Pre-treatment significantly increased the carbohydrate content. Maximum increase was observed in cooked, dried and roasted $(62.14 \mathrm{~g})$ grains and minimum was observed in roasted $(56.77 \mathrm{~g})$ grains.

\section{Dietary fiber composition}

Table 3 shows the dietary fibre composition of raw and pre-treated foxtail millet grains. Insoluble dietary fiber, total dietary fiber and resistant starch content of different pre-treated millet grains varied significantly $(\mathrm{p}<0.01)$ Insoluble dietary fiber content of raw foxtail millet grain was 10.70 g. Pre-treatment, roasting significantly increased the insoluble dietary fiber content $(12.95 \mathrm{~g})$ and whereas unaffected in cooked, dried and roasted $(10.70$ g) grains. Significant increase in insoluble dietary fiber was observed in roasted grains. It is possible that thermal processing may have caused production of Millard reaction products and thus increases its insoluble dietary fiber value (Azizah and Zainon, 1997).

Soluble dietary fiber content of raw foxtail millet grain was $0.85 \mathrm{~g}$ respectively. Pretreatment decreased the soluble dietary fiber content. Maximum decrease was observed in cooked, dried and roasted ( $0.35 \mathrm{~g})$ grains and minimum was observed in roasted $(0.65 \mathrm{~g})$ grains. Total dietary fiber content of raw foxtail millet grain was 11.55 g. Pretreatment, roasting significantly increased the total dietary fiber content $(13.60 \mathrm{~g})$ and 
decreased in cooked, dried and roasted (11.05 g) grains. Increased total dietary fiber could have resulted from the formation of enzyme resistant macromolecules containing starch, protein, lipid, and/or non-starch polysaccharides (Huber, 1991) and also due to formation of resistant starch (Ramulu and Udayasekhara, 1997).

Table.1 Pre-treatments given to millet grains

\begin{tabular}{|l|l|l|}
\hline SINo. & Pre-treatments & Methodology \\
\hline $\mathbf{1}$ & Roasting & $\begin{array}{l}\text { Foxtail millet grains were roasted in a frying pan until } \\
\text { flavour developed (4- } 6 \text { min). }\end{array}$ \\
\hline $\begin{array}{l}\text { Cooking and drying and } \\
\text { roasting }\end{array}$ & $\begin{array}{l}\text { Foxtail millet were taken and water was added twice } \\
\text { the volume of millets }(1: 2: \text { Millet: water) and cooked in } \\
\text { pressure cooker }(1 \text { whistle). After releasing the pressure } \\
\text { the hot rice was immediately transferred into sieve and } \\
\text { cold water was poured to cool the rice (to stop } \\
\text { gelatinization). Then the rice was spread on the muslin } \\
\text { cloth over blotting paper and kept under fan for } 3 \text { hours } \\
\text { to remove superficial water. Then the rice was } \\
\text { completely dried in cabinet drier at } 50{ }^{\circ} \mathrm{C} \text { for } 2 \text { and half } \\
\text { hour. Further roasted in frying pan until flavor } \\
\text { developed. }\end{array}$ \\
\hline
\end{tabular}

Table.2 Proximate composition of raw and pre-treated foxtail millet grains

\begin{tabular}{|l|c|c|c|c|c|c|}
\hline \multicolumn{1}{|c|}{ Pre-treatments } & Moisture (\%) & Protein (\%) & Fat (\%) & Ash (\%) & TDF (\%) & Carbohydrate (\%) \\
\hline Raw & $9.27 \pm 0.10$ & $16.08 \pm 0.33$ & $4.86 \pm 0.05$ & $4.94 \pm 0.002$ & $10.70 \pm 0.42$ & $54.04 \pm 0.07$ \\
\hline Roasted & $4.48 \pm 0.20$ & $15.40 \pm 0.25$ & $4.22 \pm 0.11$ & $4.93 \pm 0.00$ & $12.95 \pm 0.07$ & $56.77 \pm 0.26$ \\
\hline $\begin{array}{l}\text { Cooked,dried and } \\
\text { roasted }\end{array}$ & $3.68 \pm 0.27$ & $14.07 \pm 0.67$ & $2.71 \pm 0.02$ & $4.94 \pm 0.00$ & $10.70 \pm 0.14$ & $62.14 \pm 0.36$ \\
\hline S.Em. \pm & 0.11 & 0.26 & 0.04 & 0.00 & 0.14 & 0.14 \\
\hline C.D. & $0.40^{* *}$ & $0.90 * *$ & $0.14 * *$ & NS & $0.51 * *$ & $0.51 * *$ \\
\hline F value & 669.22 & 15.16 & 696.75 & 7.00 & 75.59 & 756.30 \\
\hline
\end{tabular}

**Significant @ $1 \%$ level, NS - Non Significant, Mean \pm SD 
Table.3 Dietary fibre composition of raw and pre-treated foxtail millet grains

\begin{tabular}{|l|c|c|c|c|}
\hline Pre-treatments & Insoluble dietary fiber (\%) & Soluble dietary fiber (\%) & Total dietary fiber (\%) & Resistant starch $(\%)$ \\
\hline Raw & $10.70 \pm 0.42$ & $0.85 \pm 0.07$ & $11.55 \pm 0.35$ & $1.04 \pm 0.06$ \\
\hline Roasted & $12.95 \pm 0.07$ & $0.65 \pm 0.07$ & $13.60 \pm 0.00$ & $2.14 \pm 0.15$ \\
\hline $\begin{array}{l}\text { Cooked, dried } \\
\text { and roasted }\end{array}$ & $10.70 \pm 0.14$ & $0.35 \pm 0.07$ & $11.05 \pm 0.21$ & $3.03 \pm 0.07$ \\
\hline S.Em. \pm & 0.14 & 0.04 & 0.13 & 0.05 \\
\hline C.D. & $0.51^{* *}$ & $0.13 * *$ & $0.47 * *$ & $0.20 * *$ \\
\hline F value & 75.59 & 38.77 & 98.63 & 288.49 \\
\hline
\end{tabular}

**Significant @ $1 \%$ level, Mean \pm SD

Table.4 Mineral composition raw and pre-treated millet grains

\begin{tabular}{|l|c|c|c|c|c|}
\hline \multicolumn{1}{|c|}{ Minerals(mg/100g) } & Calcium & Copper & Iron & Zinc & Manganese \\
\hline Raw & $32.42 \pm 0.45$ & $0.54 \pm 0.01$ & $5.75 \pm 0.04$ & $3.86 \pm 0.03$ & $1.58 \pm 0.04$ \\
\hline Roasted & $31.84 \pm 0.05$ & $0.57 \pm 0.03$ & $6.18 \pm 0.31$ & $3.99 \pm 0.19$ & $1.50 \pm 0.05$ \\
\hline Cooked, dried and roasted & $28.50 \pm 0.25$ & $0.61 \pm 0.01$ & $5.81 \pm 0.61$ & $3.92 \pm 0.04$ & $1.39 \pm 0.05$ \\
\hline S.Em. \pm & 0.17 & 0.01 & 0.22 & 0.06 & 0.02 \\
\hline C.D. & $0.59^{* *}$ & $0.03 * *$ & NS & NS & $0.09 * *$ \\
\hline F value & 150.60 & 10.09 & 1.03 & 0.98 & 12.40 \\
\hline
\end{tabular}

**Significant @ $1 \%$ level, NS - Non Significant, Mean \pm SD

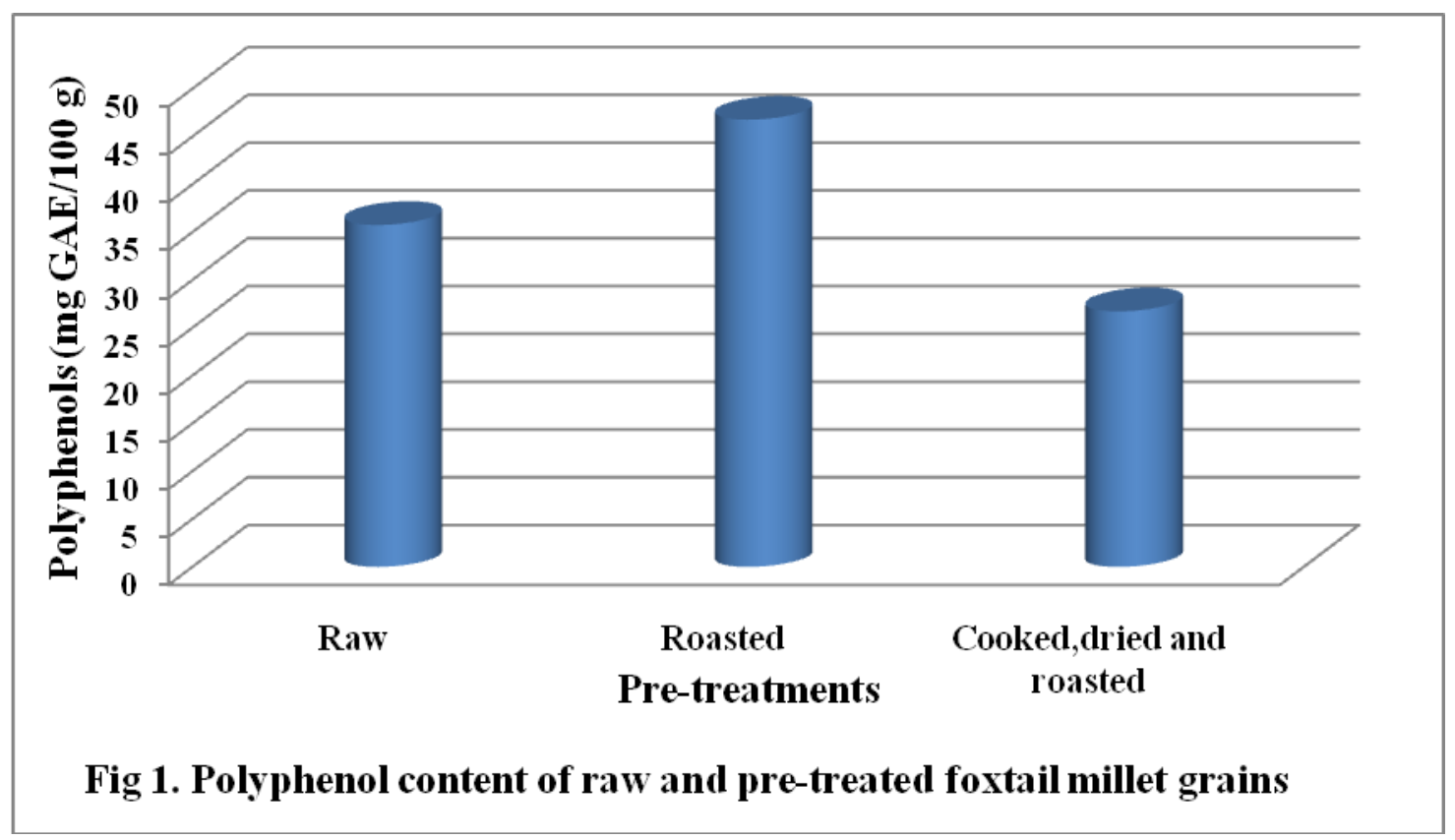




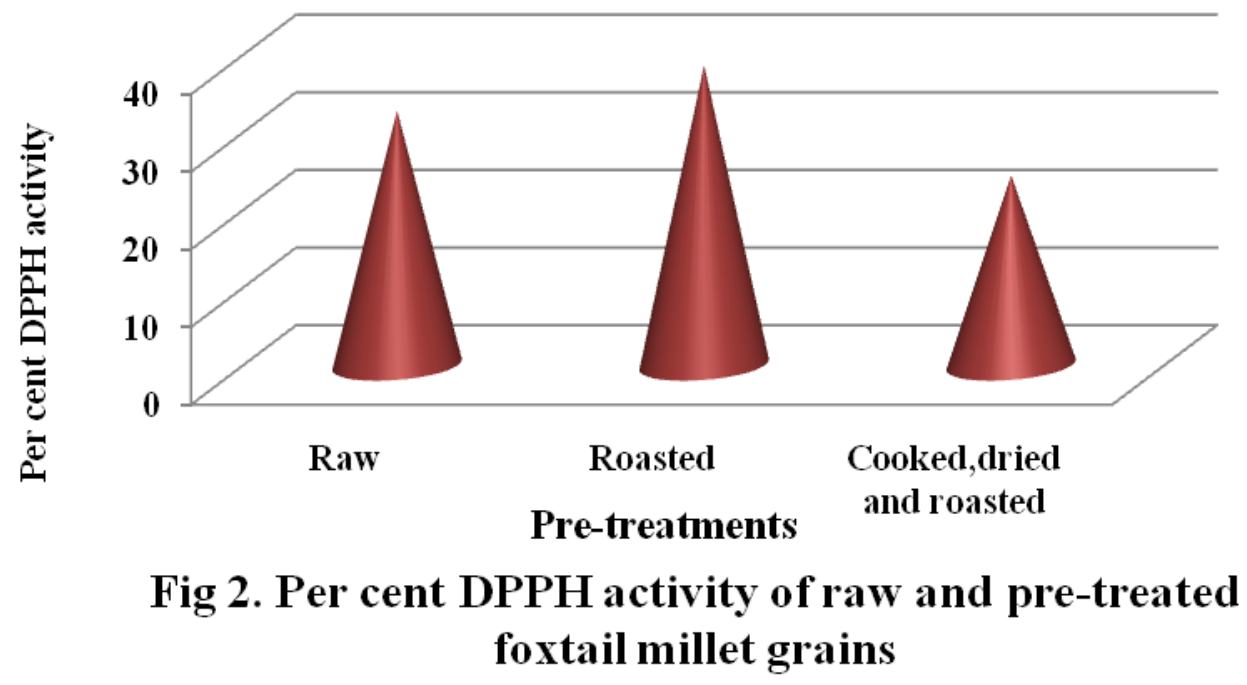

Resistant starch content of raw foxtail millet was $1.04 \mathrm{~g}$. Pre-treatment increased resistant starch significantly. Maximum increase was observed in cooked, dried and roasted $(3.03 \mathrm{~g})$ grains followed by roasted $(2.14 \mathrm{~g})$ grains. Significant increase in resistant starch may be due to altering the cooking process and amylose forms complexes with lipids (amylose-lipid complex) and this allows the amylose and linear parts of amylopectin to form crystalline structure that reduces digestibility and increase resistant starch content (Hasjimet al., 2013).

Table 4 shows mineral composition of pretreated foxtail millet grains. Calcium content of raw foxtail millet was $32.42 \mathrm{mg}$. Calcium content of different pre-treated millet grains varied significantly $(\mathrm{p}<0.01)$. Pre-treatment decreased calcium content significantly. The maximum reduction was observed in cooked, dried and roasted $(28.50 \mathrm{mg})$ grains followed by roasted $(31.84 \mathrm{mg})$ grains. As expected this may be due to leaching of nutrients. Copper content of raw foxtail millet was 0.54 $\mathrm{mg}$. Copper content of different pre-treated millet grains varied significantly $(\mathrm{p}<0.01)$. Copper content increased significantly in cooked, dried and roasted $(0.61 \mathrm{mg})$ grains whereas it decreased in roasted grains $(0.57$ $\mathrm{mg}$ ). Iron content of raw foxtail millet was $5.75 \mathrm{mg}$. There was no significant difference observed in iron and zinc content. Manganese content of raw foxtail millet was $1.58 \mathrm{mg}$. Pre-treatment decreased the zinc content. Maximum decrease was observed in cooked, dried and roasted grains $(1.39 \mathrm{mg})$ and minimum was observed in roasted grains $(1.50 \mathrm{mg})$. The reduction in the mineral contents with roasting treatments might be attributed to the loss of nutrients while treating at high temperature (Malik et al., 2002).

\section{Polyphenols and per cent DPPH activity}

Fig.1 shows polyphenol content of raw and pre-treated millet grains. Polyphenol content of raw foxtail millet was $35.76 \mathrm{mgGAE} / 100 \mathrm{~g}$ respectively. Phenolic content of different pre-treated millet grains varied significantly. Significant increase was observed in roasted grains (46.77mgGAE) whereas it decreased significantly in cooked, dried and roasted (26.73mgGAE). Similar trend was observed in DPPH activity (Fig. 2). DPPH activity of raw foxtail millet was 32.79 per cent. Pretreatment significantly increased the antioxidant activity in roasted (38.62 \%) 
grains whereas in cooked, dried and roasted grains it decreased significantly $(24.45 \%)$. Roasting significantly improved the nutraceutical properties millet by increasing its content in phenolic compounds and also its antioxidant activities (Pradeep and Guha, 2011). The results obtained were in agreement with this study. More decrease in cooked, dried and roasted grains may be due to thermo liable nature of polyphenols and antioxidants, which might have been lost on cooking (Anilakumaret al., 2007).

In conclusion, pre-treatment reduced the nutrients like protein, mineral composition and phyto chemicals however there was an effective improvement in the dietary fibre composition and resistant starch which delays the gastric emptying and slows down the digestion.

\section{References}

Anilakumar, K. R., Sarita, V., Khanum, F. and Bawa, A. S., 2007, Effect of cooking on total phenols, flavonoids and antioxidant activity in spices of Indian culinary. J. Food Sci. Technol.., 44(4):357-359.

Anonymous, 2005, Official methods of analysis of Association of Official Analytical Chemists, 20th Edn. AOAC, Washington. D. C.

Asp, N. G., Johansson, C. G., Hallmer, H. and Silgestrom, M., 1983, Rapid enzymatic assay of insoluble and soluble dietary fiber. J. Agric. Food Chem., 31:476482.

Azizah, A. H. and Zainon, H., 1997, Effect of processing on dietary fiber contents of selected legumes and cereals. Mal. J. Nutr., 3: 131-136.

Bhattacharjee, R., Khairwal, I. S., Bramel, P. J. and Reddy, K. N., 2007, Establishment of a pearl millet (Pennisetum glaucum (L.) R. Br.) core collection based on geographical distribution and quantitative traits. Euphytica., 155: 35-45.

Chandrasekara, A., Naczk, M. and Shahidi, F., 2012, Effect of processing on the antioxidant activity of millet grains. Food Chem., 133: 1-9.

Gopalan, C., Ramasastri, B.V. and Balaubramanian, S.C., 2007, Nutritive value of Indian foods. National Institute of Nutrition, ICMR, Hyderabad, pp.4245

Hasjim, J., Ai. Y. and Jane, J., 2013, Novel applications of amylose-lipid complex as resistant starch type 5. Resistant starch: sources, applications and health benefits. John Wiley and Sons, Maningat CC., $1^{\text {st }}$ Ed, pp. 79-94.

Hotz, C. and Gibson, R. S., 2007, Traditional food-processing and preparation practices to enhance the bioavailability of micronutrients in plant-based diets. $J$. Nutr., 37: 1097-1100.

Huber, G. R., 1991, Carbohydrates in extrusion processing. Food Technol., 45:160-168.

Jemima, B. M. and Indu, V. R., 2012, Nutrient and antioxidant analysis of raw and processed minor millets. Elixir Food Sci., 52:11279-11282.

Khapre, A. P., Shere, D. M. and Deshpande, H. W., 2016, Studies on effect of roasting on nutritional and antinutritional components of foxtail millet (Setaria italica). The Bioscan. 11(1): 177-179.

Kumar, K. K and Parameshwaran, P.K., 2006, Characterization of storage protein from selected varieties of foxtail millet (Setaria italic (L) Beauv). J. Agri. Sci., 77: 535-42.

Malik, M., Singh. U. and Dahiya, S., 2002, Nutrient composition of pearl millet as influenced by genotypes and cooking methods. J. Food Sci. Technol., 39: 463-468. 
Osaretin, A. T., Ebuehi. and Abosede, C. O., 2007, Effect of cooking and soaking on physical characteristics, nutrient composition and sensory evaluation of indigenous and foreign rice varieties in Nigeria. African J. Biotechnol., 6 (8):1016-1020.

Pradeep, S. R., and Guha, M., 2011, Effect of processing methods on the nutraceutical and antioxidant properties of little millet (Panicum sumatrense) extracts. Food Chem., 126:1643-1647.

Ramulu, P. and Udayasekhara, R.P. 1997, Effect of processing on dietary fiber content of cereals and pulses. Plants Human Nutr.., 50(3): 249-257.

Sade, F. O., 2009, Proximate antinutritional and functional properties of processed pearl millet (Pennisetum glaucum). $J$. Food Technol., 7(3): 92-97.

Shree, B., Rao, S. G and S. Puttaraj. 2008. Formulation and preparation of bajrapapad. Ind. J. Nutr.Dietet., 45: 221.

Veena, B., Chimmad, B.V., Naik, R. K. and Shantakumar, G., 2005. Physicochemical and nutritional studies in barnyard millet. Karnataka J. Agric. Sci., 18(1):101-105.

Yu, L., Haley, S., Perret, J., Harris, M., Wilson, J. and Qian, M., 2002, Free radical scavenging properties of wheat extracts. J. Agric. Food Chem., 50: 1619-1624.

\section{How to cite this article:}

Smita Doddamani and Nirmala B. Yenagi 2018. Nutrient Composition of Pre-treated Foxtail Millet Rice. Int.J.Curr.Microbiol.App.Sci. 7(02): 1314-1322.

doi: https://doi.org/10.20546/ijcmas.2018.702.160 